\title{
Dependence of ductile fracture toughness of a weld metal on notch root radius and inclusion content
}

\author{
B. FAUCHER, W.R. TYSON, Y. HONG ${ }^{(1)}$ and J. BOUTIN ${ }^{(2)}$ \\ Metals Technology Laboratories, CANMET, Ottawa, Canada KIA OG1; (1)Institute of Mechanics, \\ Academia Sinica, Beijing, China; ${ }^{(2)}$ Ecole Polytechnique, Montréal; now at Alcan, Jonquière, Canada
}

Received 25 November 1988; accepted 8 September 1989

\begin{abstract}
Using different fluxes of high and low basicity, two different welds have been produced with low and high inclusion content. Inclusions have been characterized in 2 and 3 dimensions, from measurements on both polished sections and on fracture surfaces. The fracture toughness is evaluated with $J$-integral, crack tip opening displacement (CTOD) and stretch zone width measurements. Ductile fracture satisfies the criterion of a critical fracture strain over a characteristic distance. These two critical values can be determined from the results obtained with blunt notch specimens. Characteristic distances are an order of magnitude larger than the inclusion spacing. This is attributed to the need to reach conditions of sustained crack growth for initiation of ductile tearing.
\end{abstract}

\section{Introduction}

Ductile fracture occurs by the coalescence of cavities that pre-existed or initiated at defects and grew during deformation of the material. Following the work of Rice and Johnson [1] relating ductile fracture toughness to inclusion parameters, several models have been derived to describe ductile fracture, recent reviews being published by Bates [2] and Garrison [3].

The micro-mechanical model used most widely is based on a "stress-modified critical strain" criterion. At initiation of ductile fracture, the plastic equivalent strain must exceed the critical fracture strain $\bar{\varepsilon}_{f}^{*}$ over a characteristic distance, $x_{0}$. The fracture strain depends on the local state of stress, $\sigma_{m} / \bar{\sigma}^{\prime}$ where $\sigma_{m}$ is the hydrostatic and $\bar{\sigma}$ the equivalent stress; the characteristic distance, $x_{0}$, is thought to be related to the mean spacing of the void initiating particles. Problems arise with the identification of $x_{0}$, which may be some multiple of the inclusion spacing [4], and for the determination of the fracture strain, which is often taken as the plane strain tensile ductility.

In this study, direct measurements on fracture surfaces will remove any ambiguity in the values of these terms. Blunt-notch specimens will be used to test the validity of the micromechanical model, as shown, for example, by Begley et al. [5], from the root radius dependence of the strain distribution at the tip of a notch. Different inclusion levels are obtained by using two different fluxes during welding.

\section{Experimental procedure}

Plates of a $19 \mathrm{~mm}$ thick ingot cast steel were welded in 4 passes by submerged arc welding with two fluxes of low (Linde 124) and high (Oerlikon OP121TT) basicity. 
Table 1. Compositions (weight \%)

\begin{tabular}{lllllllll}
\hline & $\mathrm{C}$ & $\mathrm{Mn}$ & $\mathrm{Si}$ & $\mathrm{S}$ & $\mathrm{P}$ & $\mathrm{Al}$ & $\mathrm{Ni}$ & $\mathrm{Cr}$ \\
\hline Steel & 0.14 & 1.41 & 0.24 & 0.005 & 0.014 & 0.015 & 0.22 & 0.040 \\
Electrode & 0.10 & 1.65 & 0.275 & 0.014 & 0.009 & 0.09 & 0.03 & 0.015 \\
Weld A & 0.09 & 1.27 & 0.46 & 0.012 & 0.015 & 0.012 & 0.105 & 0.040 \\
Weld B & 0.11 & 1.45 & 0.314 & 0.007 & 0.015 & 0.020 & 0.135 & 0.045 \\
\hline & $\mathrm{Cu}$ & & $\mathrm{Ti}$ & $\mathrm{V}$ & $\mathrm{Nb}$ & $\mathrm{O}$ & $\mathrm{N}$ \\
\hline Steel & 0.015 & 0.01 & 0.06 & 0.025 & - & - & - \\
Electrode & 0.02 & 0.005 & 0.005 & 0.005 & 0.063 & 0.0092 \\
Weld A & 0.064 & 0.007 & 0.024 & 0.017 & 0.021 & 0.0092 \\
Weld B & 0.065 & 0.01 & 0.035 & 0.021 & 0.021 \\
\hline
\end{tabular}

Composition of the steel, welding electrode and resulting welds $\mathrm{A}$ and $\mathrm{B}$, respectively, are given in Table 1.

Round tensile specimens, $25.4 \mathrm{~mm}$ gage length, were cut in the longitudinal direction of the welds. Three-point-bend, $B \times 2 B$, specimens were machined in the direction transverse to the weld with thickness $B=17 \mathrm{~mm}$, and through-thickness notched -either by machining or fatigue precracking- to a depth of about 60 percent of the width. Three types of bend specimens were used, as shown in Fig. 1 , by machining the notches with a flank angle of $0^{\circ}$ or $60^{\circ}$. V-grooves were machined to 10 percent of the thickness on each side of all specimens. Plane strain tensile specimens were cut also in the transverse direction, following the design of Clausing [6], with the reduced section in the weld. Mechanical tests were carried out at room temperature with a servo-hydraulic MTS computer-controlled universal testing machine. $J$-resistance curves were obtained from the bend specimens with the unloading compliance technique [7], and tensile properties were obtained according to ASTM standard method E8.

Inclusion parameters in two dimensions, including density $N_{2}$, diameter $D_{2}$ and the nearest neighbour spacing $L_{2}$, were measured on polished samples from 50 fields of $0.072 \mathrm{~mm}^{2}$, by

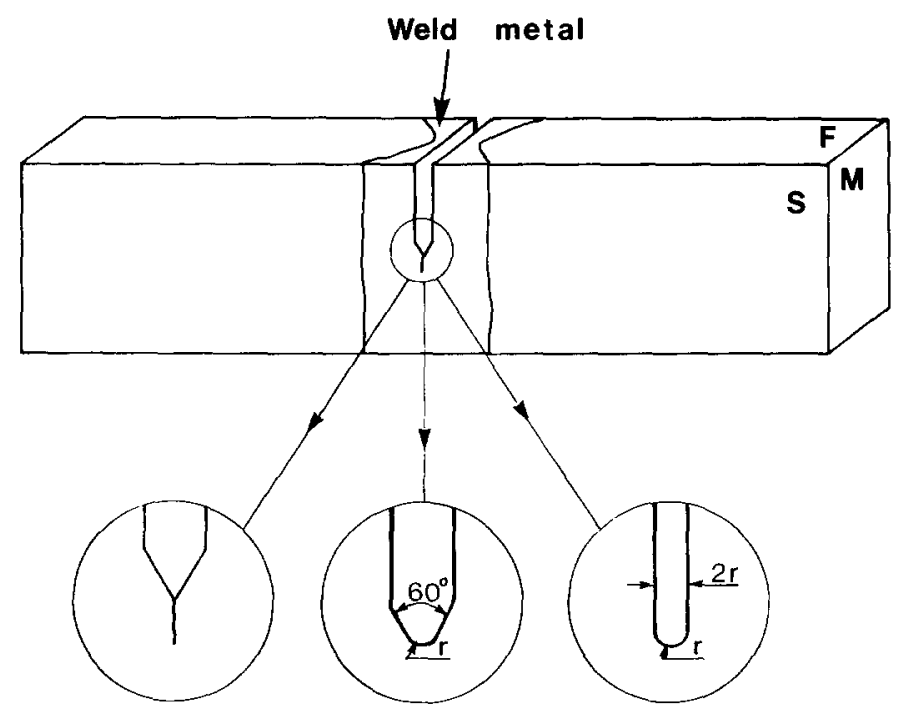

Fig. I. Orientation of bend specimens and the three types of notch. 
a Cambridge Quantimet 900 Image Analyzer with a limit of $0.05 \mu \mathrm{m}^{2}$ on inclusion area. Fractography of the bend specimens was carried out by scanning electron microscopy [8]. Photographs were taken of the stretch zone width (SZW) at $100 \times$, and of the dimples in the tearing zone at $3000 \times$. These photographs were reproduced manually on a transparency to enable quantitative measurements of the SZW, and of the size of the inclusions inside the dimples, i.e., of inclusions active in the tearing process. These measurements were performed on an IBAS Image Analyzer over the full thickness of the specimens for the SZW and a total of 700 to 1000 dimples. The fracture strain was also evaluated on the fracture surface by the technique developed by Boutin [8]. This technique is based on a simulation of the growth of cavities from inclusions on the fracture surface by stepwise dilations on the Image Analyzer. The plastic strain is related to the dilation, $d R_{p} / R_{p}$, though the equation developed by Rice and Tracey [9]:

$$
d R_{p} / R_{p}=0.28 d \bar{\varepsilon}_{p} \exp \left(1.5 \sigma_{m} / \bar{\sigma}\right)
$$

The strain necessary to initiate cavities is neglected, and the fracture strain is determined at the onset of impingement of cavities. An average stress triaxiality $\sigma_{i n} / \bar{\sigma}=0.87$ was used, which is the value at a distance of about $0.6 \delta$ from the crack tip [10], where $\delta$ is the crack tip opening displacement.

\section{Experimental results}

\subsection{Mechanical properties}

Each of the experimental results given in Table 2 is the average of two tests. The yield stress $\sigma_{v}$, the tensile strength $\sigma_{\mathrm{UTS}}$, the flow stress $\sigma_{0}\left(\sigma_{0}=\left(\sigma_{y}+\sigma_{\mathrm{UTS}}\right) / 2\right)$, the strain-hardening exponent $n$, defined by $\sigma=k \varepsilon^{n}$, and the fracture strain $\bar{\varepsilon}_{f}$, measured from the final diameter were obtained from standard tension tests. For plane strain tension specimens, the true plastic strain $\varepsilon_{p}$ was evaluated by $\varepsilon_{p}=\ln \left(T_{0} / T\right)$ where $T_{0}$ is the initial value of the reduced thickness, and $T$ is measured in the middle of the specimen, in the plane strain region. The equivalent strain is $\bar{\varepsilon}_{p}=(2 / \sqrt{3}) \varepsilon_{p}[11]$. The plane strain fracture strain, $\bar{\varepsilon}_{f}^{*}$, is the equivalent strain just before the specimen starts to crack.

$J$-resistance curves are shown in Fig. 2 for the three types of bend specimens used. For each weld material, specimens of various radii were tested as well as four specimens with a fatigue precrack. The plots in Fig. 2 follow the ASTM standard construction for $J_{k}$ [12], except for the blunting line which is defined as $J=4 \sigma_{0} \Delta a$, where $a$ is the crack length. This blunting line shows better agreement with the experimental results of Fig. 2, and with the analysis of Heerens et al. [13]. The results of the four pre-cracked specimens have been grouped together to calculate the regression line. From these results, standard $J_{l}$ values are obtained. However, the round notch specimens do not qualify for the evaluation of

Table 2. Mechanical properties of the two welds

\begin{tabular}{lllllll}
\hline Weld & $\sigma_{y}(\mathrm{MPa})$ & $\sigma_{\mathrm{UTS}}(\mathrm{MPa})$ & $\sigma_{0}(\mathrm{MPa})$ & $n$ & $\varepsilon_{j}$ & $\bar{\varepsilon}_{j}^{*}$ \\
\hline A & 521 & 611 & 566 & 0.14 & 1.14 & 0.62 \\
B & 543 & 644 & 593 & 0.13 & 1.13 & 0.76 \\
\hline
\end{tabular}




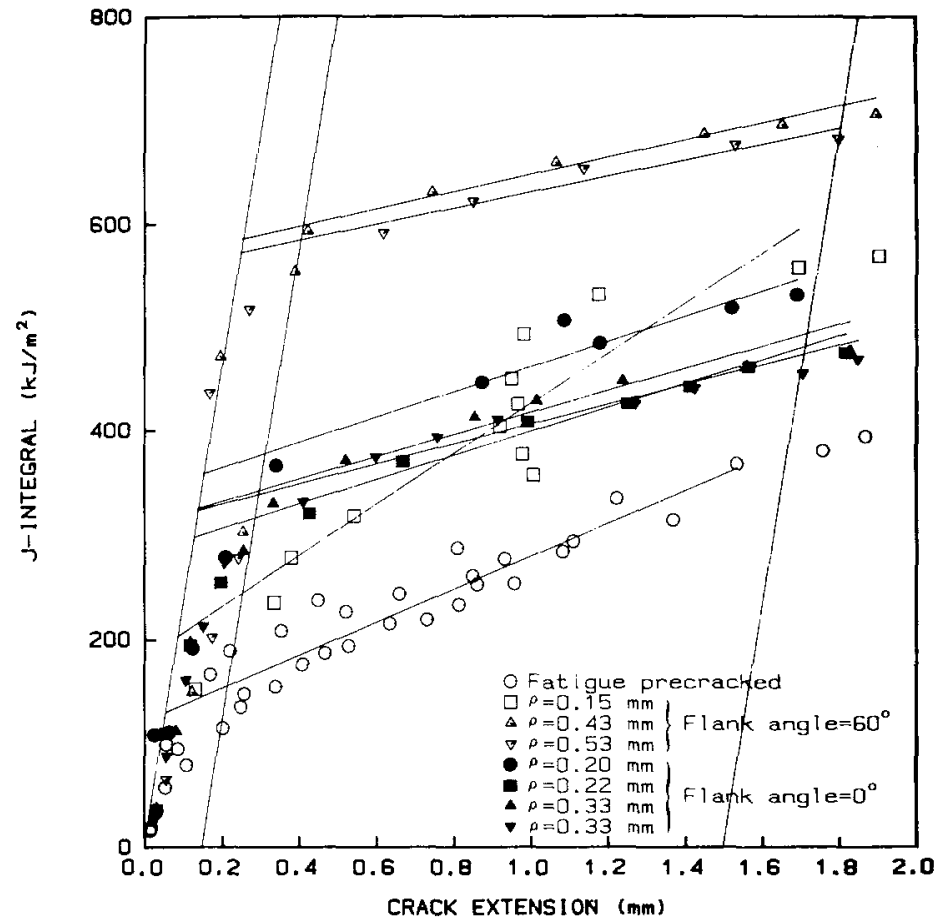

(a)

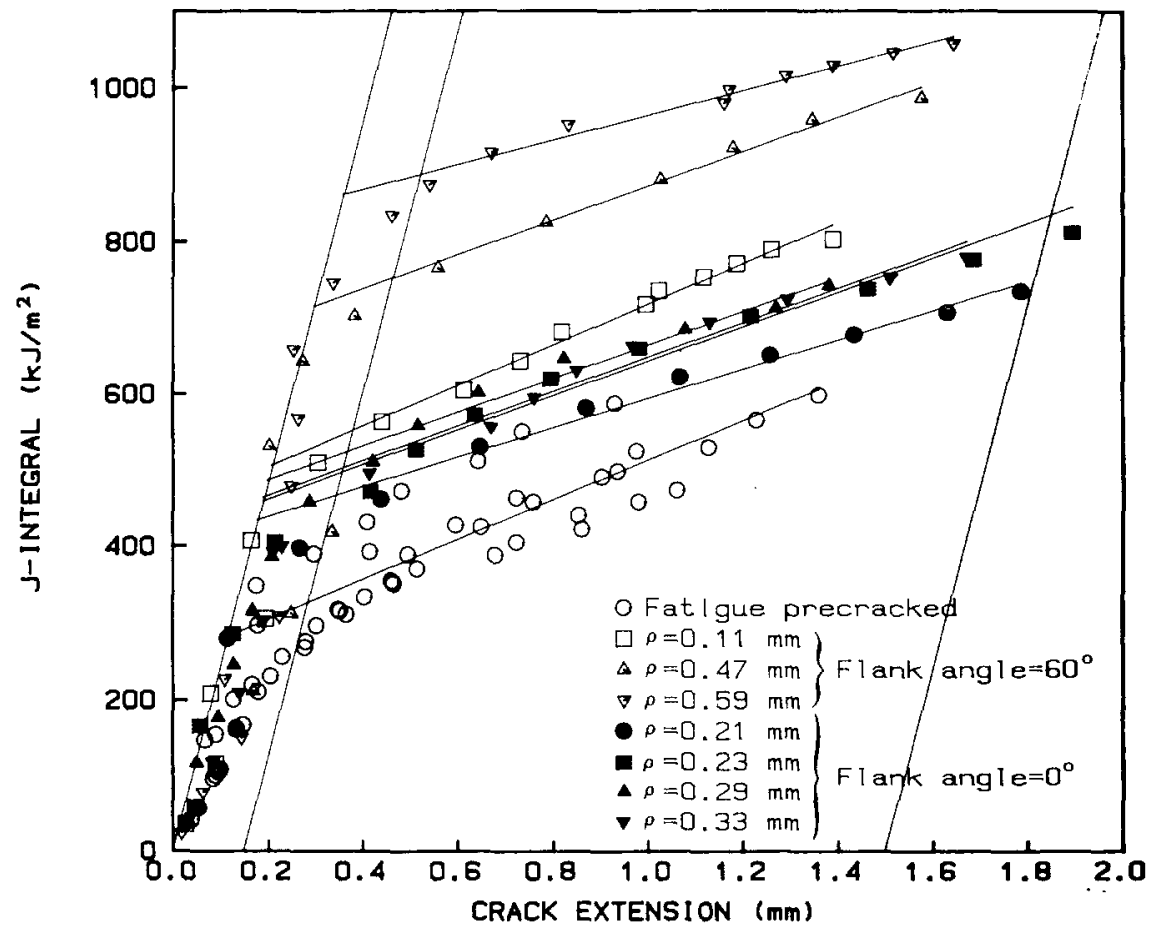

(b)

Fig. 2. Standard plots of $J$-resistance curves with the blunting lines defined as $J=4 \sigma_{0} \Delta a$ for (a) Weld A a (b) Weld B. The plots for fatigue precracked specimens include results from four specimens. 
Table 3. Fracture toughness for various notch geometries

\begin{tabular}{|c|c|c|c|}
\hline Weld & Notch & $J_{c}\left(\mathrm{~kJ} / \mathrm{mm}^{2}\right)$ & CTOD $(\mathrm{mm})$ \\
\hline A & $60^{\circ} \quad r=0.15 \mathrm{~mm}$ & 204 & 0.225 \\
\hline A & $60^{\circ} \quad r=0.43 \mathrm{~mm}$ & 586 & 0.587 \\
\hline $\mathrm{A}$ & $60^{\circ} \quad r=0.53 \mathrm{~mm}$ & 573 & 0.605 \\
\hline A & $0^{\circ} \quad r=0.20 \mathrm{~mm}$ & 359 & 0.429 \\
\hline$\Lambda$ & $0^{\circ} \quad r=0.22 \mathrm{~mm}$ & 297 & 0.357 \\
\hline A & $0^{\circ} \quad r=0.33 \mathrm{~mm}$. & 323 & 0.429 \\
\hline A & $0^{\circ} \quad r=0.33 \mathrm{~mm}$ & 325 & 0.382 \\
\hline A & Fatigue precracked & $131 \pm 20$ & $0.151 \pm 0.023$ \\
\hline B & $60^{\circ} \quad r=0.11 \mathrm{~mm}$ & 506 & 0.482 \\
\hline B & $60^{\circ} \quad r=0.47 \mathrm{~mm}$ & 715 & 0.677 \\
\hline B & $60^{\circ} \quad r=0.59 \mathrm{~mm}$ & 861 & 0.829 \\
\hline B & $0^{\circ} \quad r=0.21 \mathrm{~mm}$ & 435 & 0.480 \\
\hline B & $0^{\circ} \quad r=0.23 \mathrm{~mm}$ & 459 & 0.494 \\
\hline B & $0^{\circ} \quad r=0.29 \mathrm{~mm}$ & 487 & 0.543 \\
\hline B & $0^{\circ} \quad r=0.33 \mathrm{~mm}$ & 465 & 0.499 \\
\hline B & Fatigue precracked & $283 \pm 35$ & $0.300 \pm 0.037$ \\
\hline
\end{tabular}

standard $J_{I c}$ because of their round notches and also because the " $J$ capacity" was exceeded for the specimen size used. Nevertheless, a critical value of $J, J_{t}$, was obtained in the same way as $J_{I C}$. The critical values of $J$ are indicated in Table 3, together with the associated values of the CTOD.

\subsection{Quantitative microscopy}

Typical inclusion micrographs are shown in Fig. 3. Results of the 2-dimensional and 3-dimensional quantitative analysis are listed in Table 4, for the three orthogonal planes identified in Fig. 1. The 3-D diameters, $D_{3}$, and densities, $N_{3}$, were obtained from 3-D size distributions, calculated from the 2-D distributions by the Schwartz-Saltykov method while the 3-D particle spacing, $L_{3}$, was calculated from the relation $L_{3}=0.554 N_{3}^{-1 / 3}$ [14]. The particles are almost spherical, with a shape factor close to 1 and the same diameters in the three orthogonal planes. Typical particle distributions are shown in Fig. 4 for the two welds. The number of particles is much larger, and the size only slightly smaller in the weld with an acidic (A) flux than with a basic (B) one.

Table 4. Inclusion parameters

\begin{tabular}{llllllll}
\hline Weld & $\begin{array}{l}D_{2} \\
(\mu \mathrm{m})\end{array}$ & $\begin{array}{l}N_{2} \\
\left(\mu \mathrm{m}^{-2}\right)\end{array}$ & $\begin{array}{l}L_{2} \\
(\mu \mathrm{m})\end{array}$ & $\begin{array}{l}\text { Shape } \\
\text { factor }\end{array}$ & $\begin{array}{l}N_{3} \\
\left(\mu \mathrm{m}^{-3}\right)\end{array}$ & $\begin{array}{l}D_{3} \\
(\mu \mathrm{m})\end{array}$ & $\begin{array}{l}L_{3} \\
(\mu \mathrm{m})\end{array}$ \\
\hline A S & $0.452 \pm 0.106$ & 0.0700 & 1.90 & 0.999 & 0.119 & 0.584 & 1.13 \\
A M & $0.503 \pm 0.129$ & 0.0460 & 2.43 & 0.958 & 0.071 & 0.649 & 1.34 \\
A F & $0.503 \pm 0.122$ & 0.0655 & 2.05 & 0.938 & 0.099 & 0.659 & 1.22 \\
average & $0.486 \pm 0.119$ & 0.0604 & 2.13 & 0.965 & 0.096 & 0.631 & 1.22 \\
\hline B S & $0.540 \pm 0.165$ & 0.0258 & 3.20 & - & 0.0358 & 0.722 & 1.68 \\
B M & $0.502 \pm 0.127$ & 0.0178 & 3.86 & 0.971 & 0.0263 & 0.678 & 1.86 \\
B F & $0.514 \pm 0.120$ & 0.0130 & 4.49 & 0.958 & 0.0188 & 0.691 & 2.08 \\
average & $0.519 \pm 0.137$ & 0.0189 & 3.85 & 0.965 & 0.0270 & 0.697 & 1.88 \\
\hline
\end{tabular}




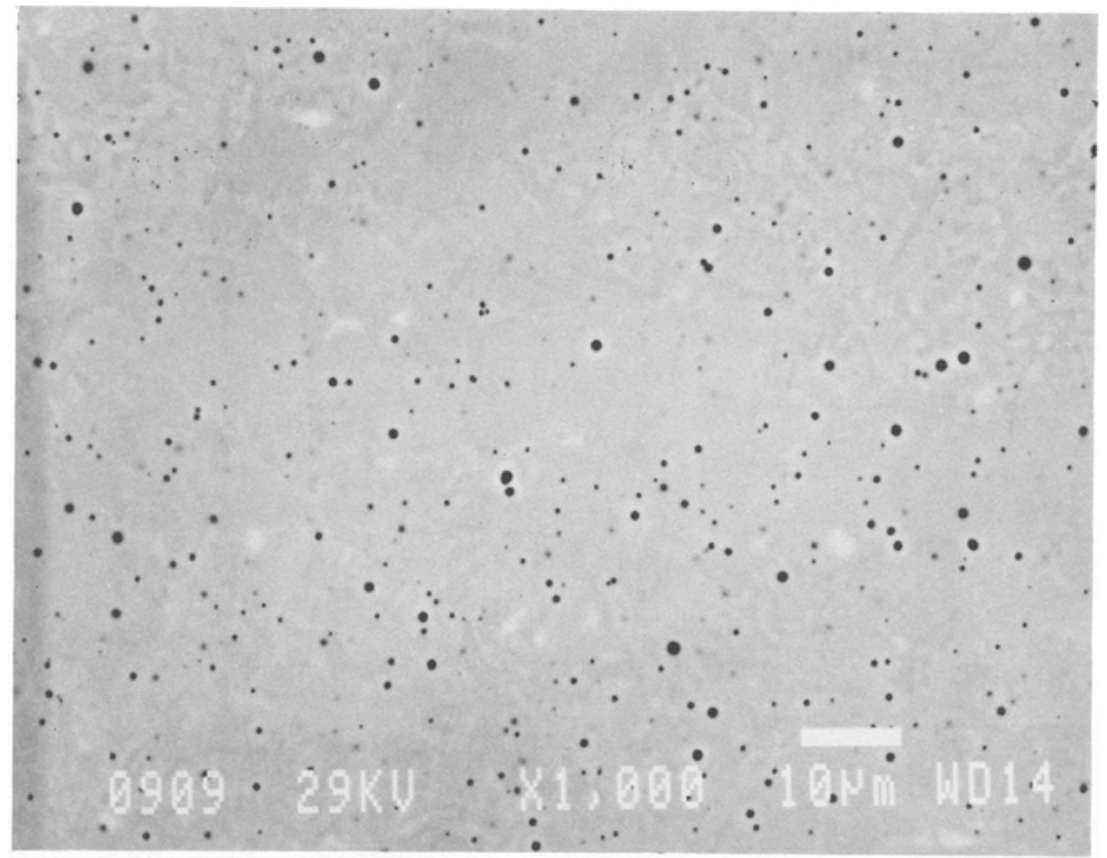

(a)

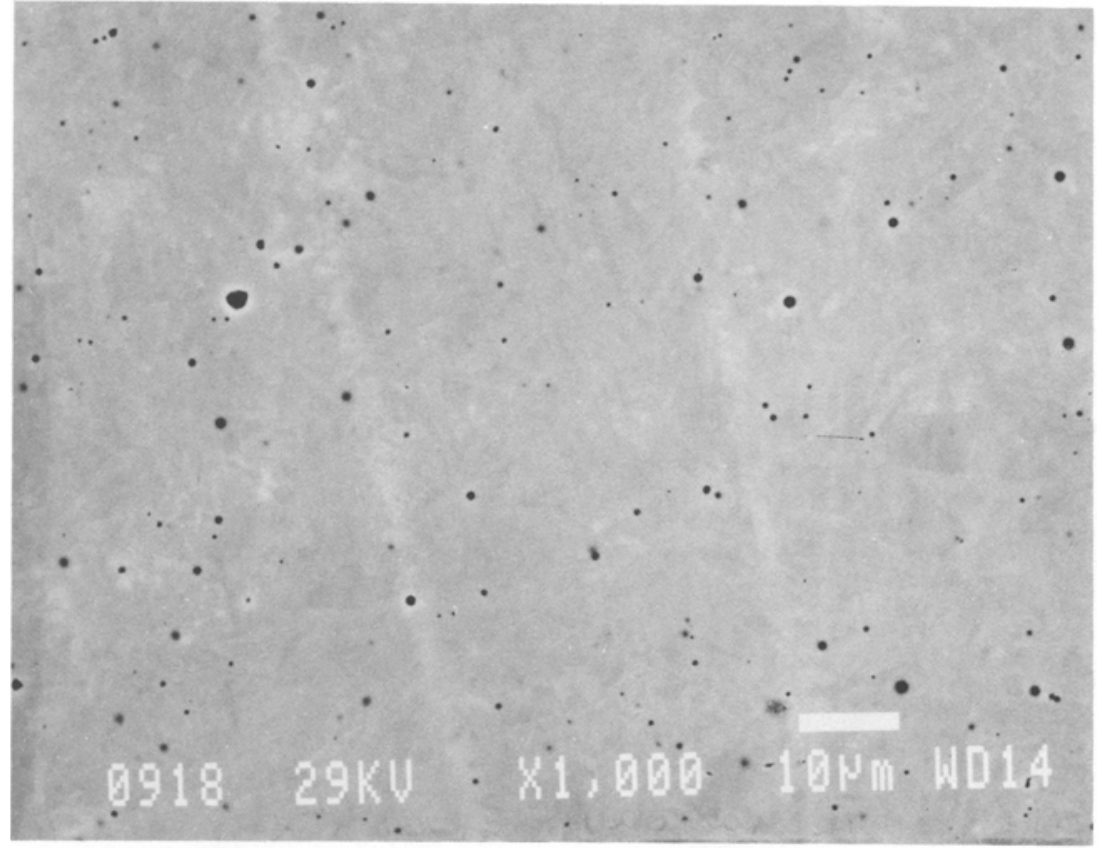

(b)

Fig. 3. Inclusions on polished surfaces of (a) Weld A and (b) Weld B.

Results of the fractographic analysis for bend specimens are indicated in Table 5, and typical dimple areas are shown in Fig. 5. The fracture strains were obtained by the method of Boutin [8], and the values of $\delta_{i}$ were taken as twice the stretch zone width, which corresponds truly to the initiation. The values are averages of three sets of measurements on fatigue pre-cracked specimens. The surface roughness parameter, estimated from the linear 


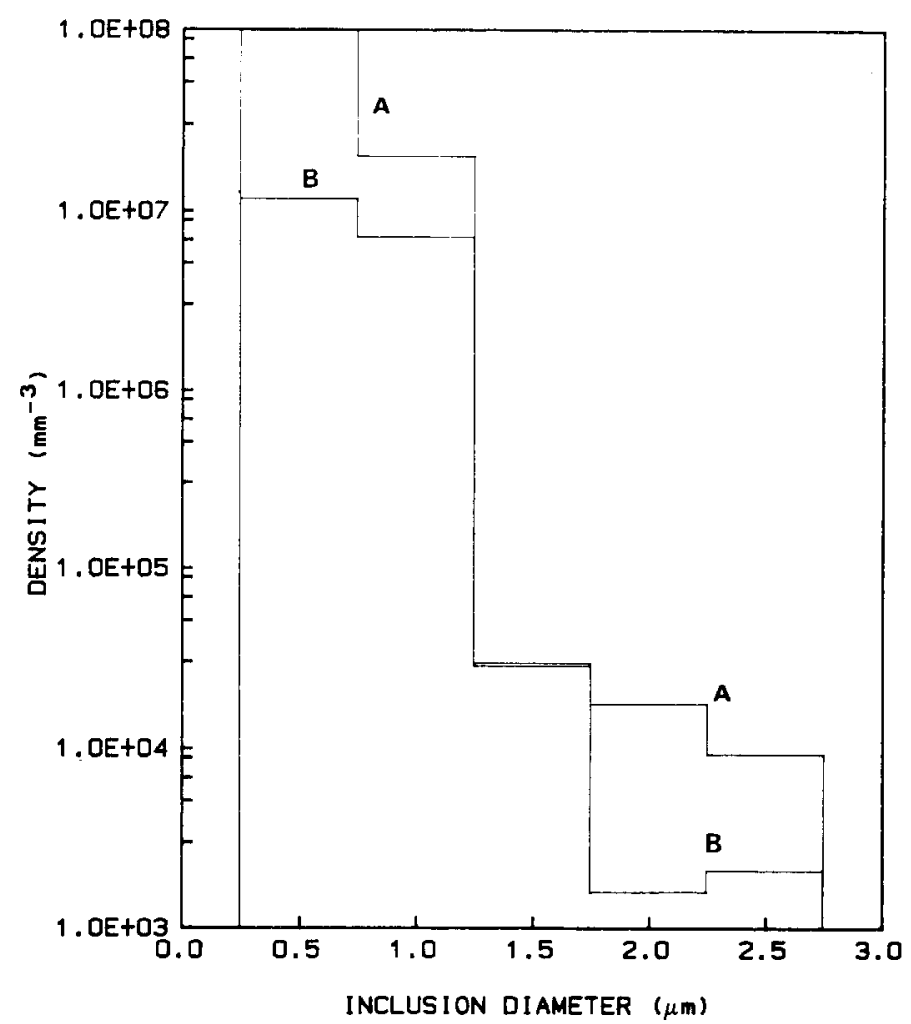

Fig. 4. Three-dimensional size distribution of inclusions in the two weld metals.

Table 5. Fractographic analysis of bend specimens

\begin{tabular}{lllll}
\hline Weld & $D_{s}(\mu \mathrm{m})$ & $L_{s}(\mu \mathrm{m})$ & $\bar{\varepsilon}_{f}$ & $\delta_{i}(\mathrm{~mm})$ \\
\hline A & $1.01 \pm 0.05$ & $6.0 \pm 0.9$ & $0.87 \pm 0.06$ & $0.089 \pm 0.014$ \\
B & $1.08 \pm 0.04$ & $7.6 \pm 0.9$ & $0.88 \pm 0.09$ & $0.176 \pm 0.028$ \\
\hline
\end{tabular}

roughness parameter [15], has been used to evaluate the average distance between inclusions on the fracture surface, $L_{s}$, from the number of inclusions per unit of projected area [8]. The average diameter of the inclusions measured on the fracture surfaces, $D_{s}$, is significantly larger than the value measured on polished samples $\left(D_{2}\right.$ or $D_{3}$ in Table 4$)$, and their average spacing is larger than the 3-D particle spacing. This implies that the smallest inclusions do not initiate dimples, as discussed below.

\section{Discussion}

\subsection{Fractography}

There are significant differences between measurements on the fracture surfaces and inclusion parameters: the inclusions active in the tearing process (i.e., measured on the fracture surface, as in Fig. 5) have a diameter about 1.6 times the 3-D value obtained from polished surfaces (Fig. 3). This indicates that dimples are not formed at inclusions smaller 


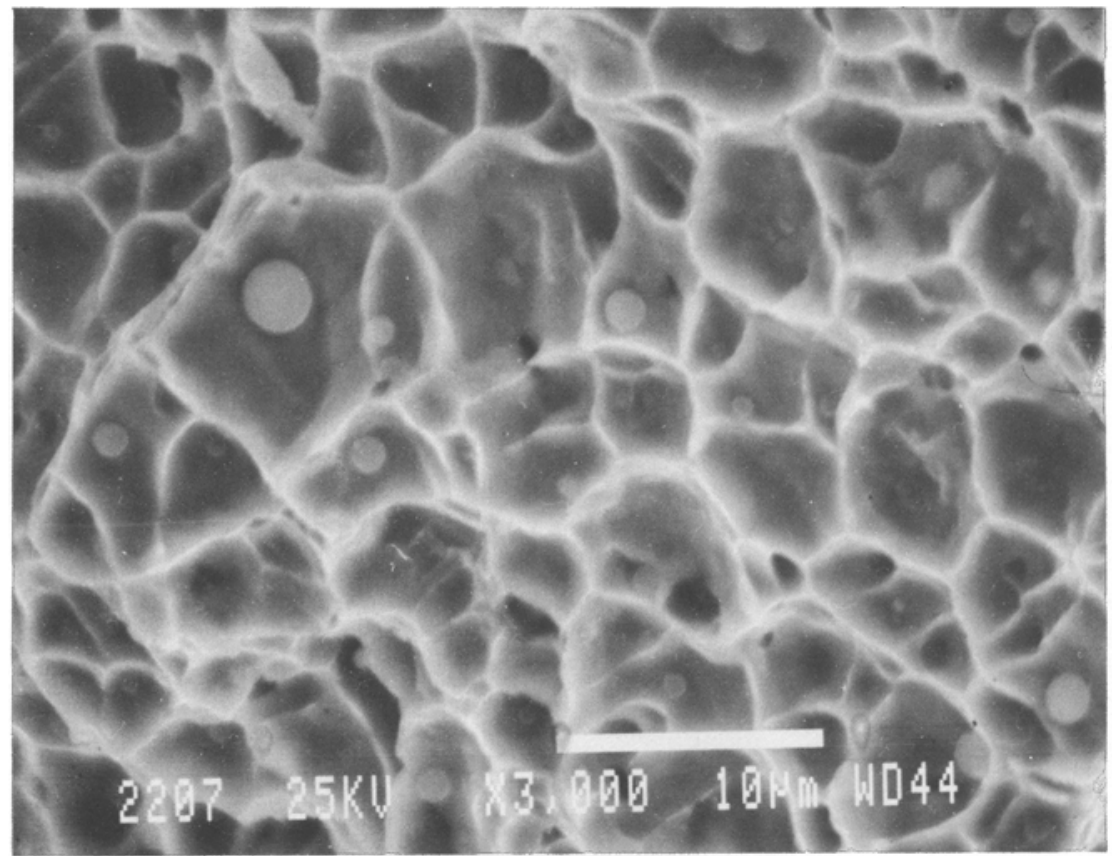

(a)

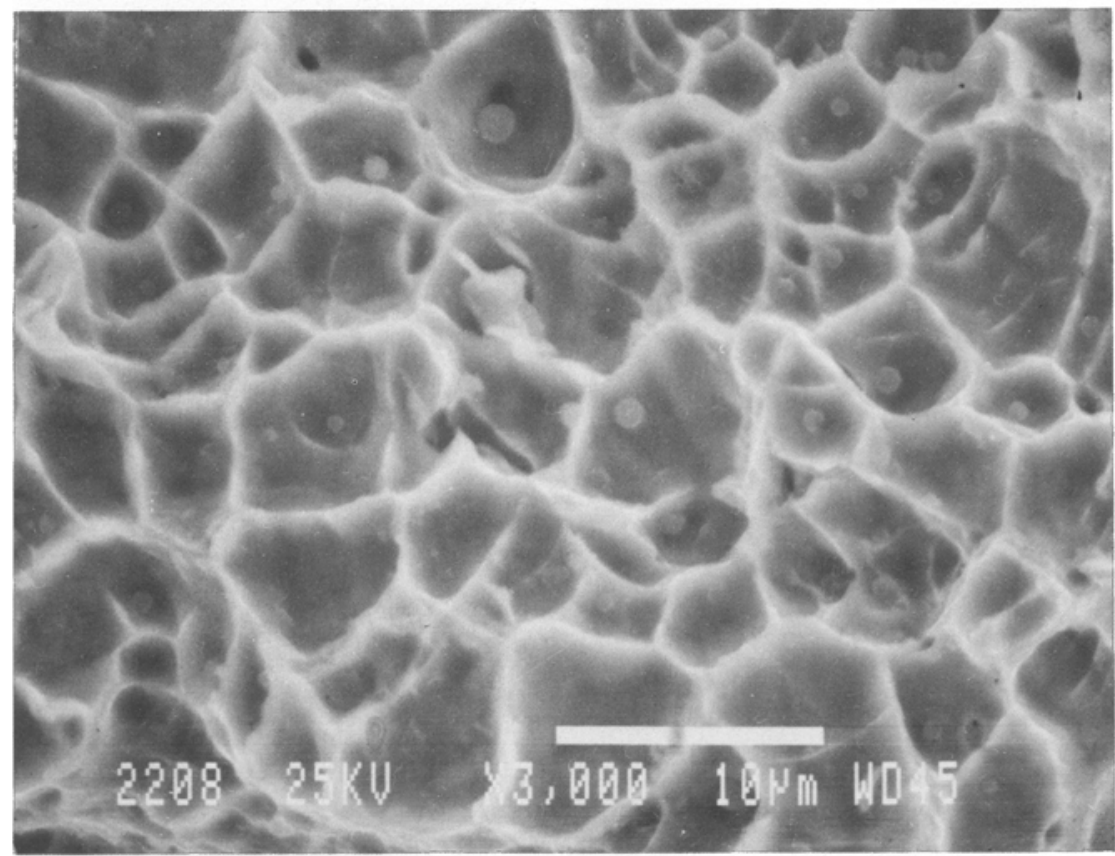

(b)

Fig. 5. Typical dimples with some of the initiating inclusions for (a) Weld A and (b) Weld B.

than a minimum size. As a result, the spacing between these active inclusions is 4-5 times the 3-D spacing and 2-3 times the 2-D spacing in Table 4 calculated from measurements on polished sections. This larger spacing provides more opportunity for cavity growth, therefore larger ductility and higher toughness than would be anticipated if all inclusions nucleated voids. From the distribution of inclusions shown in Fig. 4, it is possible to 
estimate the minimum size of active inclusions to be slightly over $1.0 \mu \mathrm{m}$. This minimum size should be related to the mechanical properties of the weld deposit investigated and to the properties of the inclusions. In relating experimental results to theoretical models, it is important to recognize that there could be more inclusions on a polished surface than there are active inclusions in the process of ductile fracture.

CTOD, $\delta$ and $J$-integral values have been related as $\delta=d_{n} J / \sigma_{0}$ where $d_{n}$ depends on mechanical properties $[11,13]$. From the experimental results in Tables 2 and $3, d_{n}$ should be about 0.60 , which is much larger than the value of 0.45 calculated from their workhardening coefficient $[11,13]$. This is probably due to the difficulty in evaluating this coefficient for materials that have a tensile curve with a Lüders plateau. The CTOD's measured on the fracture surfaces (Table 5) are significantly lower than the CTOD's measured in a mechanical test (Table 3). The difference may result partly from experimental uncertainties and from differences in the point of measurement. The CTOD on the fracture surface corresponds to the onset of the ductile tearing process by linking of voids to the blunting crack, while the $\delta$ value from a mechanical test is obtained from the $J$-resistance curve by linear back extrapolation to a blunting line (Fig. 2) using $\delta=d_{n} J / \sigma_{0}$. This value actually corresponds to the CTOD after some ductile crack extension, hence to a larger value, as observed.

\subsection{Fracture strain and critical distance}

The critical distance, $x_{0}$, over which the fracture strain must be achieved for initiation of ductile tearing can be determined from the results obtained with blunt-notch specimens. Santhanam and Bates [16] have shown that at a distance $x$ from the crack tip, smaller than the radius $\rho$, the equivalent strain is

$$
\bar{\varepsilon}=\bar{\varepsilon}_{\max } \exp (-C x / \rho)
$$

where the constant $C$ is given by $C=1.28(\pi-\beta) / \sqrt{3}, \beta$ being the flank angle. From Rice [17], the maximum strain at rounded crack tips can be expressed as a function of the $J$-integral as

$$
\varepsilon_{\max }=\varepsilon_{y}\left[\alpha(n) J /\left(\sigma_{y} \varepsilon_{y} \rho\right)\right]^{1 /(1+n)}
$$

where $\alpha(n)=(n+0.5)(n+1.5) \Gamma(n+0.5) /[\Gamma(0.5) \Gamma(n+1)]$ and $\varepsilon_{y}=\left(1-v^{2}\right) \sigma_{y} / E$ with $E$ and $v$ being, respectively, Young's modulus and Poisson's ratio for the material. Considering that in plane strain $\bar{\varepsilon}=2 \varepsilon / \sqrt{3}$, the equivalent strain at a distance $x$ of a round notch of radius $\rho$ is obtained as a function of $J$ by combining (1) and (2) as

$$
\bar{\varepsilon}=(2 / \sqrt{3}) \varepsilon_{y}\left[\alpha(n) J /\left(\sigma_{y} \varepsilon_{y} \rho\right)\right]^{1 /(1+n)} \exp (-C x / \rho)
$$

Assuming that ductile tearing initiates at $J=J_{c}$ when $\bar{\varepsilon} \geqslant \bar{\varepsilon}_{f}$ over the distance $x \leqslant x_{0}$, the critical value of $J$ is given by

$$
J_{c}=m \sigma_{y} \rho \exp \left[(1+n) C x_{0} / \rho\right],
$$




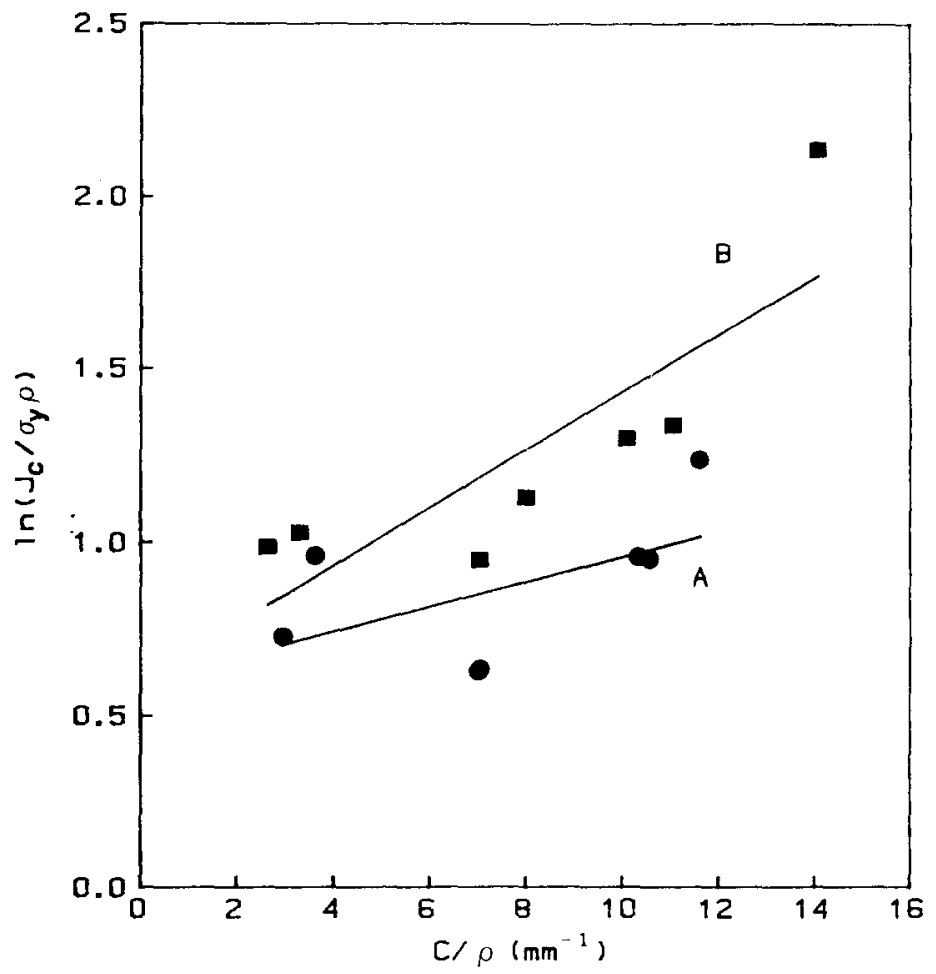

Fig. 6. Plots of the critical fracture toughness measured with round-notch specimens, according to (6).

where

$$
m=\left[(\sqrt{3} / 2)^{1+n} / \alpha(n)\right]\left(\bar{\varepsilon}_{f} / \bar{\varepsilon}_{y}\right)^{n} \bar{\varepsilon}_{f}
$$

From (4), one obtains

$$
\ln \left(J_{c} / \sigma_{y} \rho\right)=\ln m+(1+n) C x_{0} / \rho
$$

The results of Table 3 are plotted according to (6) in Fig. 6. The parameters $(1+n) x_{0}$ and In $m$ have been calculated by linear regression. From these parameters, values of $x_{0}$ and $\bar{\varepsilon}_{f}$ are shown in Table 6 for the two welds. The uncertainty quoted in these values relates to the 50 percent confidence interval. The uncertainty is relatively large, and is a consequence of the small number of test results and the difficulty to determine precisely a value for $J_{c}$ in Fig. 2. Nevertheless, these values are in good agreement with results from other measurements. Fracture strains agree surprisingly well with the values obtained on the fracture surfaces, and they are only slightly larger than the plane strain values of Table 2 . They agree

Table 6. Results from round-notch specimens

\begin{tabular}{llllll}
\hline Weld & $n$ & $\alpha(n)$ & $\bar{\varepsilon}_{f}$ & $x_{0}(\mu \mathrm{m})$ & $x_{0} / \delta$ \\
\hline A & 0.14 & 0.883 & $0.85 \pm 0.11$ & $31 \pm 15$ & 0.35 \\
B & 0.13 & 0.880 & $0.87 \pm 0.12$ & $73 \pm 16$ & 0.41 \\
\hline
\end{tabular}


also with the calculations of Rice and Johnson who predict a fracture strain of about 1.0 (Fig. 7 of [1]) at the normalized distances $\left(x_{0} / \delta\right)$ of Table 6.

Critical distances (Table 6) are compatible with the model of Rice and Johnson (Fig. 9 of [1]), provided the void-nucleating particles have the spacings reported in Table 6 . However, values of $x_{0}$ are much larger than inclusion spacings, even those measured on the fracture surface (Table 5), roughly 5 times for Weld A and 10 times for Weld B. It seems, therefore, difficult to relate the characteristic distance, hence the toughness, directly to any inclusion measurement. Bates [2] has developed a model in which it is assumed that the initiation of ductile tearing occurs only when conditions for sustained crack growth are met; i.e., instability of the ligament between two successive voids must be attained simultaneously. The use of this model requires knowledge of initial void diameter and of void diameters after coalescence. Approximate values are, respectively, the average inclusion diameter and the inter-particle spacing. With the values of $D_{3}$ and $L_{3}$ from Table 4 , the calculated CTOD's are about 0.002 and $0.005 \mu \mathrm{m}$ for Welds $\mathrm{A}$ and $\mathrm{B}$, respectively. However, with the values of $D_{s}$ and $L_{s}$ from Table 5 measured directly on the fracture surface, the respective values of $\delta_{i}$ become 62 and $156 \mu \mathrm{m}$, which are only slightly lower than the measured values of Table 5 . Bates' model, although very sensitive to the actual diameters used, can explain the discrepancy between characteristic distances and inclusion spacings. However, only the inclusions participating in the tearing process (as discussed in Section 4.1 above) should be considered in modelling ductile fracture. It is therefore, difficult at present to determine a priori the fracture toughness from inclusion measurements.

\section{Conclusions}

Ductile fracture toughnesses of two weld metals have been shown to correlate very well with the concept of attaining a critical fracture strain over a characteristic distance.

The critical fracture strain may be obtained either from plane strain tensile tests, or from fractography combined with quantitative metallography, or from measurements using blunt notch specimens. This last analysis also provides a good estimate of the characteristic distance.

For the two welds tested, the characteristic distances are consistent with a criterion for crack growth developed by Bates [2]. However, the size and spacing of inclusions active in the tearing process must be known to predict fracture toughness. In the present work, these values have been found to be significantly larger than inclusion parameters measured on a polished surface, but are in agreement with measurements carried out on the fracture surface.

\section{Acknowledgement}

The help of the technical staff of the Metals Technology Laboratories is gratefully acknowledged, particularly the assistance of J.A. Gianetto, R.F. Orr, and D.E. Dolan for the preparation of the welds, C.R. Trinque and G. Weatherall for the mechanical testing, and Dr. M. Shehata and B. Casault for inclusion measurements. 


\section{References}

1. J.R. Rice and M.A. Johnson in Inelastic Behavior of Solids, M.F. Kanninen, W.F. Adler, A.R. Rosenfield and R.I. Jaffee (eds.), McGraw-Hill, New York (1970) 641-72.

2. R.C. Bates, in Fracture: Interactions of Microstructure, Mechanisms and Mechanics, J.M. Wells and J.D. Landes (eds.), The Metallurgical Society of AIME, New York (1984) 117-55.

3. W.M. Garrison, Journal of Physics and Chemistry of Solids 48, 11 (1987) 1035-74.

4. R.O. Ritchie, W.L. Server and R.A. Wullaert, Metallurgical Transactions 10A (1979) 1557-70.

5. J.A. Begley, W.A. Logsdon and J.D. Landes, in Flaw Growth and Fracture, ASTM STP 631 (1977) 112-120.

6. D.P. Clausing International Journal of Fracture Mechanics 6, 1 (1970) 71-85.

7. B. Faucher and W.R. Tyson, in Elastic-Plastic Fracture Test Methods: The User's Experience, ASTM STP 856, E.T. Wessel and F.J. Loss (eds.) (1985) 278-293.

8. J. Boutin, Ph.D thesis, Ecole Polytechnique, Montréal (1988).

9. J.R. Rice and D.M. Tracey, Journal of the Mechanics and Physics of Solids 17 (1969) 201-217.

10. R.O. Ritchie and A.W. Thompson, Metallurgical Transactions 16A (1985) 233-248.

11. J.W. Hancock and D.K. Brown, Journal of the Mechanics and Physics of Solids 31, 1 (1983) 1-24.

12. ASTM Standard Test Method for $J_{I_{c}}$, a Measure of Fracture Toughness (E813-81), Philadelphia (1981).

13. J. Heerens, K.-H. Schwalbe and A. Cornec, in Fracture Mechanics: Eighteenth Symposium, ASTM STP 945 , D.T. Read and R.P. Reed (eds.) Philadelphia (1988) 374-389.

14. E.E. Underwood, Quantitative Stereology, Addison-Wesley, Reading, Mass. (1970).

15. S.M. El-Soudani, Metallography 7 (1974) 271-311.

16. A.T. Santhanam and R.C. Bates, Materials Science and Engineering 41 (1979) 243-250.

17. J.R. Rice, Journal of Applied Mechanics, Transactions of ASME (1968) 379-386.

Résumé. A l'aide de flux différents de forte et faible basicité, on a produit deux soudures à faible et forte teneur inclusionnaire. Les inclusions sont caractérisées en 2 et 3 dimensions par des mesures sur coupes polies et sur les surfaces de rupture. La ténacité à la rupture est évaluée par l'intégrale $J$, l'ouverture critique en fond de fissure (CTOD) et la mesure de la zone d'étirement. La rupture ductile satisfait la condition qu'une déformation critique de rupture soit atteinte sur une distance caractéristique. Ces deux valeurs critiques peuvent être déterminées à partir des résultats obtenus sur éprouvettes avec rayon d'entaille. Les distances caractéristiques sont un ordre de grandeur plus grandes que les distances inter-inclusionnaires. On attribue cette différence à la nécessité de satisfaire les conditions de croissance soutenue de la fissure pour l'initiation de la rupture ductile. 